\title{
Evaluation of Customer Relationship Management's Performance under Networked Manufacturing
}

\author{
Jinzhao An \\ School of Management, Northwest University for Nationalities \\ Lanzhou 730124, China \\ Tel: 86-931-8331169_E-mail: anjinzhao6@163.com
}

\begin{abstract}
Networked manufacturing is an advanced manufacturing technology, and efficient customer relationship management is critical for networked manufacturing's resource allocation and scheduling. Evaluation of customer relationship management's performance under networked manufacturing and effective optimization measures are preconditions for improving on CRM's performance. Development process's quality, operational process's quality, customer relationship's quality and emergency ability are critical factors of CRM's performance under networked manufacturing. Evaluating CRM's performance should build index system based on these four factors and make grey correlative analysis combined with analytic hierarchy process. The performance evaluation way proposed is feasible and effective, and combines the advantage of quantitative analysis and qualitative analysis.
\end{abstract}

Keywords: Networked Manufacturing, Customer Relationship Management, Grey Correlative Analysis, Relevance

\section{Introduction}

Customer relationship management of networked manufacturing is important for resources optimum allocation and scheduling. Customer classification according to the customer characteristics is the basis of CRM. The CRM's performance evaluation is a multipurpose and multilevel evaluating process. The critical factors of CRM's performance have fuzziness, so it has to build a scientific index system and use an evaluating method combining the advantage of qualitative and quantitative analysis. This research studies the critical factors of the CRM's performance and builds a effective index system according to the factors. And study the evaluating process of CRM's performance with grey correlative analysis method combined with analytic hierarchy process method.

\section{Evaluation Index System of CRM under Networked Manufacturing}

The performance of CRM under networked manufacturing is restricted by the Development process's quality, operational process's quality, customer relationship's quality and emergency ability. Evaluating of the performance of CRM under networked manufacturing must study the critical factors in all aspects (Zhang,2007,PP.2455-2458).

\subsection{Quality of development process}

The evaluation of CRM under networked manufacturing should considering the whole life cycle of the system. Before the operation of CRM, the quality of the development process is the critical factors for the performance evaluation.

During the development process, whether the development method is effective, whether the customer demand analysis is effective, whether the controlling measures is effective, whether the whole organization structure is supportive, are important for the CRM's performance in future. All of these aspects must be examined during the evaluation.

\subsection{Quality of operational process}

The CRM's operational process quality is the primary foundation for the system's performance. So evaluation of CRM's operational process quality is key job for the CRM's performance evaluation.

During the operational process, CRM's hardware quality, reliability, expendability, human-computer interface, data veracity, timelessness, maintainability, environmental suitability, information integration quality, and so on, are the important factors which must be concerned.

\subsection{Quality of customer relationship}

The quality of operational process and development process is evaluation in the sight of life cycle. It is essential to evaluate the CRM's performance from the customer relationship quality under networked manufacturing. 
Study the CRM's customer relationship quality form three aspects. They are customer relationship cost, customer conservation rate and customer loyalty.

\subsection{Emergency ability}

The CRM should provide well capacity of emergency early warning and response.

First, the CRM should collect the customer data, and be capable of data mining for early warning according to the clue of emergency; then, provide the response measures suggestion according to the characteristics of networked manufacturing resources and customer relationship, in purpose of success loss control.

According to the four aspects, build the hierarchical structure of the index system. Destination layer is customer relationship performance; criteria layer contains development process quality, operational process quality, customer relationship quality and emergency ability. Strategy layer contains the subsection index as stayed above.

This study use four example programs evaluation to explain the practicability of the index system, and use the simulation data to explain the evaluation method proposed. The qualities of the four programs are described by the four index aspects as stayed above.

\section{Grey Correlative Analysis of Customer Relationship}

At first, determine the evaluation criteria. Shown as Table.1.

Organize the experts to evaluate according to the indexes and calibrations, the results are shown as Table.2

\subsection{Data normalization}

The grey correlative analysis demand the data is dimensionless. So data normalization is essential. Convert the data in Tab.2 to data columns which are dimensionless, equative degree, positively additive(Zan,2008,PP.49-50).

Data contained in Tab. 1 is extremely large style. The larger the performance of CRM is stronger. Set up $\mathrm{d}_{\mathrm{ij}}$ as initial data, $\mathrm{u}_{\mathrm{ij}}$ as normal data, $\mathrm{M}_{\mathrm{j}}$ as the $\mathrm{j}$-th index's maximum $(\mathrm{i}=1,2, \ldots, 4 ; \mathrm{j}=1,2, \ldots, 4)$.

$$
\mathrm{u}_{\mathrm{ij}}=\mathrm{d}_{\mathrm{ij}} / \mathrm{M}_{\mathrm{j}}
$$

After converting, the normalization data is shown as Table.3.

\subsection{Determine the incidence coefficients}

Customer relationship performance index system could be decomposed into four indexes, $A_{1}, A_{2}, A_{3}, A_{4}$.every index contains one program's evaluation data in four index aspects(Tang,2008,PP.10-12).

A1:

$\left\{\mathrm{X}_{1}\right\}=\left\{x_{1}(1) \quad x_{1}(2) \quad x_{1}(3) \quad x_{1}(4)\right\}$;

$\mathrm{A}_{2}$ :

$\left\{\mathrm{x}_{2}\right\}=\left\{x_{2}(1) \quad x_{2}(2) \quad x_{2}(3) \quad x_{2}(4) \quad\right\}$;

$\mathrm{A}_{3}$ :

$\left\{\mathrm{x}_{3}\right\}=\left\{x_{3}(1) \quad x_{3}(2) \quad x_{3}(3) \quad x_{3}(4) \quad\right\}$;

$\mathrm{A}_{4}$ :

$\left\{\mathrm{x}_{4}\right\}=\left\{x_{4}(1) \quad x_{4}(2) \quad x_{4}(3) \quad x_{4}(4) \quad\right\}$.

Appoint the reference data column $x_{0}$ from $x_{1}, x_{2}, x_{3}, x_{4}$ :

$$
x_{0}=\left(x_{0}(1), x_{0}(2), \cdots, x_{0}(k)\right) \text {. }
$$

$x_{0}$ could be one of $x_{1}, x_{2}, \cdots x_{n}$ or their linear combination. Choose the largest as the reference data column. Then, $\left\{\mathrm{x}_{0}\right\}=\{1,1,1,1\}$.

Compute the incidence coefficient according to (2).

$$
\xi_{i}(\mathrm{k})=\frac{\operatorname{mimin}_{i}{ }_{k}}{\left|\mathrm{x}_{0}(\mathrm{k})-\mathrm{x}_{\mathrm{i}}(\mathrm{k})\right|+0.5 \operatorname{mamaxx}_{\mathrm{i}}(\mathrm{k})-\mathrm{x}_{\mathrm{i}}(\mathrm{k}) \mid}
$$




\subsection{Determine the index system weight}

Determine the index system weight with analytic hierarchy process method. The process of definition of weight is as follows.

$$
k_{i j}=\left\{\begin{array}{l}
0 \\
1 \quad 0, \text { the } \mathrm{i} \text {-th index is less important than the } \mathrm{j} \text {-th index; } 1 \text {, the } \mathrm{i} \text {-th index is equal to the } \mathrm{j} \text {-th index; } 2, \text { the } \mathrm{i} \text {-th } \\
2
\end{array}\right.
$$

index is more important than the $\mathrm{j}$-th index(Peng, 1999, PP.10-12).

According to the actual project background, definite the comparison matrix shown as Tab.4.

Then, $\mathrm{K}_{\max }=7, \mathrm{~K}_{\min }=2$, according to (3):

$$
\mathrm{Q}_{i j}=\left\{\begin{array}{cc}
1+2\left(\mathrm{k}_{\mathrm{i}}-\mathrm{k}_{\mathrm{j}}\right) / 7 & \mathrm{k}_{\mathrm{i}}=\mathrm{k}_{\mathrm{j}} \\
1 /\left[1-2\left(\mathrm{k}_{\mathrm{i}}-\mathrm{k}_{\mathrm{j}}\right) / 7\right] & \mathrm{k}_{\mathrm{i}}<\mathrm{k}_{\mathrm{j}}
\end{array}\right.
$$

\subsection{Compute the relevance}

Computer the relevance $r_{1}, r 2, r 3, r 4$, according to the formula shown as follows (Hu, 1993, PP.26-29):

$$
r_{i}=\frac{1}{N} \sum_{i=1}^{N} \xi_{i}(k)
$$

\section{Conclusion}

According the magnitude sequence of $r_{1}, r_{2}, r_{3}, r_{4}$, determine the optimum program. The evaluation method of CRM's performance utilizes the advantage of grey correlative analysis and analytic hierarchical process. The evaluation process studies the Development process's quality, operational process's quality, customer relationship's quality and emergency ability. It's an effective and practical evaluating way for CRM's performance evaluation under networked manufacturing.

\section{Acknowledgment}

Supported by the fund of technology projects, Education Department of Jiangxi province (No: GJJ09181).

\section{References}

Hu Shuhua. (1993).Weighting Comprehensive Evaluation Method and Its Applications for Product Design Evaluation. China Mechanical Engineering. Dec, 1993, pp.26-29.

Peng Shaoyong. (1999). A New Method for Evaluation of Design Alternatives Based on the Grey Relational Analysis. Journal of Huazhong University of Science and Technology, July, 2009. Pp.43-45. (Peng, 1999, PP.10-12)

Tang Yonghong. (2008). Application of Performance Evaluation Matrix and Relativity Performance Matrix in CRM. China Market, Vol. 1, No. 45, pp.10-12.

Zan Xin. (2008). Research on Customer Relation Value based on Fuzzy Comprehensive Evaluation. Shanghai Management Science, Vol. 1, No. 1, PP. 49-50.

Zhang Chuncheng. (2007). A Framework of Performance Measurement System for Networked Manufacturing. Agile Enterprise. Vol. 12.No. 2, pp. 2455-2458.

Table 1. Importance calibration

\begin{tabular}{|c|c|}
\hline Calibration $\mathrm{a}_{\mathrm{ij}}$ & definition \\
\hline $1-3$ & Very feeble \\
$3-5$ & feeble \\
$5-7$ & normal \\
$7-9$ & Relative strong \\
$9-10$ & Very strong \\
\hline
\end{tabular}


Table 2. Every program's index data

\begin{tabular}{|l|c|c|c|c|}
\hline & 1 & 2 & 3 & 4 \\
\hline Development process & $\mathrm{a}_{11}$ & $\mathrm{a}_{12}$ & $\mathrm{a}_{13}$ & $\mathrm{a}_{14}$ \\
\hline Operational process & $\mathrm{a}_{21}$ & $\mathrm{a}_{22}$ & $\mathrm{a}_{23}$ & $\mathrm{a}_{24}$ \\
\hline Customer relationship & $\mathrm{a}_{31}$ & $\mathrm{a}_{32}$ & $\mathrm{a}_{33}$ & $\mathrm{a}_{34}$ \\
\hline Emergency ability & $\mathrm{a}_{41}$ & $\mathrm{a}_{42}$ & $\mathrm{a}_{43}$ & $\mathrm{a}_{44}$ \\
\hline
\end{tabular}

Table 3. Normalizing data

\begin{tabular}{|c|c|c|c|c|}
\hline & 1 & 2 & 3 & 4 \\
\hline Development process & $x_{1}(1)$ & $x_{2}(1)$ & $x_{3}(1)$ & $x_{4}(1)$ \\
\hline Operational process & $x_{1}(2)$ & $x_{2}(2)$ & $x_{3}(2)$ & $x_{4}(2)$ \\
\hline Customer relationship & $x_{1}(3)$ & $x_{2}(3)$ & $x_{3}(3)$ & $x_{4}(3)$ \\
\hline Emergency ability & $x_{1}(4)$ & $x_{2}(4)$ & $x_{3}(4)$ & $x_{4}(4)$ \\
\hline
\end{tabular}

Table4. Judgment matrix

\begin{tabular}{|c|c|c|c|c|c|c|}
\hline & $\mathrm{Q}_{\mathrm{i} 1}$ & $\mathrm{Q}_{\mathrm{i} 2}$ & $\mathrm{Q}_{\mathrm{i} 3}$ & $\mathrm{Q}_{\mathrm{i} 4}$ & $\sum_{j=1}^{4} Q_{i j}$ & $\omega_{i}$ \\
\hline $\begin{array}{c}\text { Development } \\
\text { process }\end{array}$ & 1 & 0.41 & 0.47 & 1 & 2.88 & 0.15 \\
\hline $\begin{array}{c}\text { Operational } \\
\text { process }\end{array}$ & 2.43 & 1 & 1.29 & 2.43 & 7.15 & 0.38 \\
\hline $\begin{array}{c}\text { Customer } \\
\text { relationship }\end{array}$ & 2.14 & 0.78 & 1 & 2.14 & 6 & 0.32 \\
\hline $\begin{array}{c}\text { Emergency } \\
\text { ability }\end{array}$ & 1 & 0.41 & 0.47 & 1 & 2.88 & 0.15 \\
\hline
\end{tabular}

